\title{
Avulsion Fracture of the Anterior Tibial Tuberosity to a Young Athlete
} Ayoub Mjidila*, Ismail Kabbaj, Med Reda Galiou, M. Boufettal, Reda Allah Bassir, Kharmaz, O. Lamrani, Med Saleh Berrada

Department of Orthopaedic Surgery, Ibn Sina Hospital, Mohammed 5 University, Faculty of medicine of Rabat. Rabat - Morocco

DOI: $10.36347 /$ sasjs.2021.v07i01.006

| Received: 13.12.2020 | Accepted: 31.12.2020 | Published: 19.01.2021

*Corresponding author: Ayoub Mjidila

Avulsion fracture of the anterior tibial tuberosity is rare. Diagnosis is based on clinical features and standard radiology. The authors report a case of 17 years old teenager, who presents an avulsion of the anterior tibial tuberosity. The treatment consisted in open reduction of the tibial tubercle then fixing it by screwing. The functional results were good.

Keywords: Avulsion fracture, anterior tibial tuberosity, Osgood-Schlatter.

Copyright $\left({ }^{\circ} 2021\right.$ The Author(s): This is an open-access article distributed under the terms of the Creative Commons Attribution 4.0 International License (CC BY-NC 4.0) which permits unrestricted use, distribution, and reproduction in any medium for non-commercial use provided the original author and source are credited.

\section{INTRODUCTION}

Avulsion fracture of the anterior tibial tuberosity is a rare lesion in late-growing athletic adolescents with a marked male predominance $[1,2]$. It accounts for $3 \%$ of fractures of the proximal end of the tibia [2]. The clinical picture is suggestive. The standard $\mathrm{x}$-ray confirms the diagnosis. Treatment is surgical in the displaced forms.

\section{CASE PRESENTATION}

He is a 17-year-old teenager, with no particular history, presenting to the emergency department with severe pain in his left knee following a jump during a basketball game. Clinical examination revealed a painful swelling knee (Fig-1), with active knee extension deficit and unremarkable vasculo-nervous examination. X-rays of the knee, antero-posterior and lateral views revealed a tearing fracture of the anterior tibial tuberosity classified II A according to the Ogden classification (Fig-2).

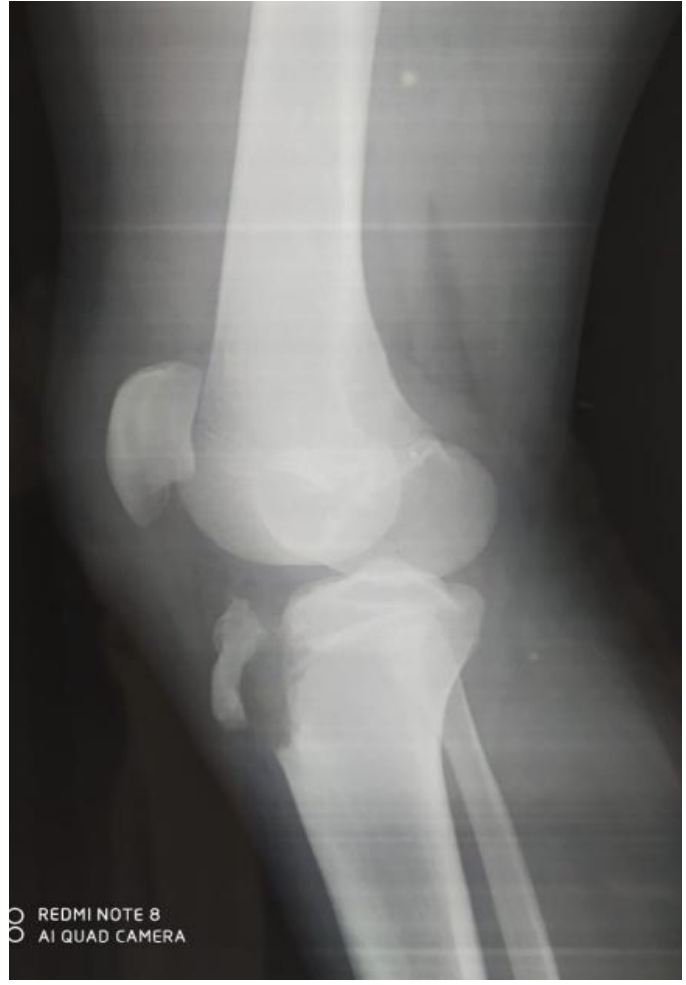

Fig-1: Emergency department $X$-ray in lateral view of the left knee 


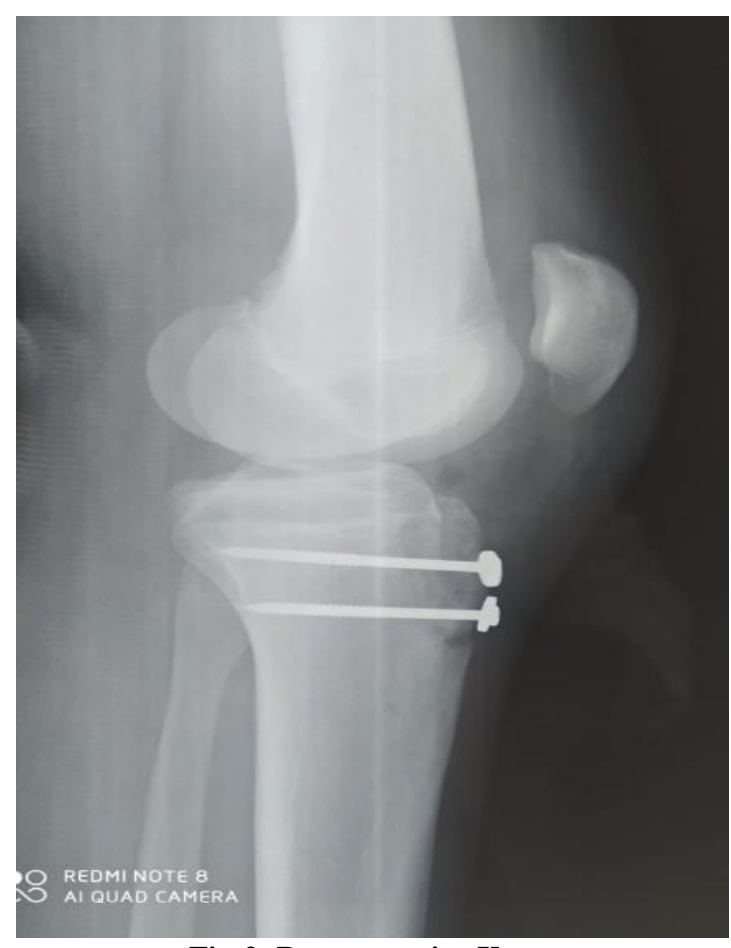

Fig-2: Post-operative X-ray

The patient underwent open reduction of the tuberosal fragment via the midline approach using two screws (Fig-3). The surgical exploration has not found associated lesions. The post-operative courses were simple. The immobilization of the knee with the zimmer splint was six weeks, support was allowed for the third week. Rehabilitation with the knee up to 30 degrees the first 3 weeks was allowed. Consolidation was obtained on day 45 . With a ten-month follow-up, the mobility of the knee was normal.

\section{DISCUSSION}

The anterior tibial tuberosity tear fracture is rare, the risk of avulsion is greater when the proximal tibial growth cartilage is closed, as the ATT is less resistant to sudden traction exerted by the quadriceps $[1,3]$. Osgood-Schlatter pathology and tibial tuberosity avulsion are two completely different entities, the first form being a predisposing pathology to avulsion [3, 4, 5].

Their association is frequent [6]. Ogden's classification [1] makes it possible to classify tear-off fractures, according to the feature of the fracture and bone displacement, into three types. Frankl et al., [9] defined a type $\mathrm{C}$ corresponding to a rupture of the patellar tendon associated with avulsion.

The lesional mechanism is a sudden tensioning of the patellar tendon. According to the position of the knee, Lefort [7] differentiated between tornings on a straight knee (pure apophyseal) and tearing on a bent knee (epiphyseal). Depending on the mechanism, other lesions may be associated, including avulsion of the patellar tendon and meniscal lesions [8].
The acute clinical picture is very suggestive. The patient presents with a swollen knee with a deficit of active knee extension. Patients with Ogden's Type I injury are able to extend the knee against gravity, but not against resistance. However, patients with type II and III lesions are unable to extend the knee regardless of the situation [10]. The lateral knee x-ray confirms the diagnosis and classifies the fracture according to Ogden.

Orthopedic treatment is reserved for type IA fractures and more rarely for strictly non-displaced type II or III fractures. The average duration of immobilization found in the different series is 6 weeks (4-8) without support. Surgical treatment is reserved for all displaced fractures and almost all type II and III fractures [11]. The lateral parapatellar approach is recommended to avoid the section of the infra-patellar nerve threads of the saphenous nerve [12]. The functional results are good; however long-term complications have been described in the literature: patella baja, atrophy of the quadriceps, iterative fracture and genu recurvatum [11].

\section{CONCLUSION}

Avulsion fractures of the anterior tibial tuberosity in adolescent age are rare. Osgood-Schlatter disease is a risk factor for these fractures. Surgical treatment is systematic for all displaced tears in order to allow the anatomical and functional restoration of the knee.

\section{Conflict of interests: None.}

\section{REFERENCES}

1. Ogden JA, Tross RB, Murphy MJ. Fractures of the tibial tuberosity in adolescents. J Bone Joint Surg Am. 1980; 62:205-15.

2. McKoy BE, Stanitski CL. Acute tibial tubercle avulsion fractures. Orthop Clin N Am. 2003; 34: 397-403

3. Ogden JA, Southwick WO. Osgood-Schlatter's disease and tibial tuberosity development. Clin Orthop. 1976; 116: 180-9.

4. Abalo A, Akakpo-Numado KG, Dossim A, Walla A, Gnassingbe K, Tekou AH. Avulsion fractures of the tibial tubercle. Journal of Orthopaedic Surgery. 2008 Dec;16(3):308-11.

5. Zrig M, Annabi H, Ammari $\mathrm{T}$, Trabelsi $\mathrm{M}$, Mbarek M, Hassine HB. Acute tibial tubercle avulsion fractures in the sporting adolescent. Archives of orthopaedic and trauma surgery. 2008 Dec 1;128(12):1437-42.

6. Peyroux LM, Mathevon H. Tearing fracture of the anterior tibial tuberosity in adolescents. J Traumatol Sport. 1997; 14: 217-22.

7. Lefort G. Sport and apophyseal pathology in children and adolescents. Teaching Conference 1998. Cah Teacher Sofcot. 1998; 66: 191-203. 
8. Jalgaonkar AA, Dachepalli S, Al-Wattar Z. Atypical tibial tuberosity fracture in an adolescent. Sports Medicine. 2011; 34: e215-e8.

9. Frankl U, Wasilewski SA, Healy WL. Avulsion fracture of the tibial tubercle with avulsion of the patellar ligament. J Bone Joint Surg. 1990; 72A: 1411-3.

10. Fnini S, Sirajhak M, Messoudi A, Arssi M, Hassoun J, Garche, A, Largab A. Neglected avulsion fracture of the anterior tibial tuberosity. $\mathrm{J}$ Traumatol Sport. 2011; 28: 257-260.

11. Bauer T, Milet A, Odent T, Padovani JP, Glorion C. Avulsion fracture of the anterior tibial tuberosity in adolescents: 22 cases and review of the literature. Rev Chir Orthop. 2005; 91: 758-67.

12. Wiss DA, Zionts L. Type III fractures of the tibial tubercle in adolescents. J Orthop Trauma. 1991; 5:475-9. 